\title{
Does social vulnerability for caries predict caries status of children in sub-urban Nigeria?
}

Morenike Oluwatoyin Folayan', Olujide Olusesan Arije²

${ }^{1}$ Obafemi Awolowo University, Department of Child Dental Health, Ile-Ife, Nigeria

${ }^{2}$ Obafemi Awolowo University Teaching Hospitals Complex, Department of Community Health, Ile-Ife, Nigeria

\begin{abstract}
It is important to identify groups of people vulnerable to a disease condition. Aim: To determine the association between social vulnerability to caries and caries status of children in Ile-Ife, Nigeria. Methods: A composite vulnerability index for caries was developed using data generated for 992 children. Wilks' Lambda test to verify relationship between vulnerability and its variables. Logistic regression analysis was conducted to determine if the social vulnerability for caries index was a good predictor for caries status. Results: The social vulnerability to caries index could not predict caries status. The study found that sex, age and number of siblings were the significant predictors of caries status in the study population. Females (AOR: $1.63 ; 95 \% \mathrm{Cl}: 1.08-2.46 ; \mathrm{p}=0.02$ ) and children with more than two siblings had higher odds of having caries (AOR: $2.61 ; 95 \% \mathrm{Cl}: 1.61-$ $4.24 ; p<0.001$ ) while children below 5 years had lower odds of having caries (AOR: $0.62 ; 95 \% \mathrm{Cl}$ : $0.39-1.00 ; p=0.05)$ Conclusions: The social vulnerability index for caries could not predict the caries status of children in the study population. Sensitive tools to identify children with caries in the study population should be developed.
\end{abstract}

Keywords: Social Vulnerability. Indexes. Dental Caries. Child. Nigeria.

\section{Introduction}

Received for publication: May 23, 2016 Accepted: August 22, 2016

Correspondence to: Morenike Oluwatoyin Folayan Department of Child Dental Health, Obafemi Awolowo University, Ile-Ife, Nigeria

Phone: +234 7062920394 E-mail: toyinukpong@yahoo.co.uk
Vulnerability is by definition a measure of possible future harm ${ }^{1}$. It is the ability to anticipate, resist, cope with and respond to a hazard ${ }^{2}$ and the intrinsic predisposition of an individual or a collective to be susceptible to damage when exposed to a hazard ${ }^{3}$. It has been studied in the context of physical and social vulnerabilities. Physical vulnerability takes into consideration the risk of exposure to natural disasters while social vulnerability studies the impact of social inequalities ${ }^{4,5}$.

Social vulnerability is a multifaceted concept often defined as the entirety of the social deficits faced by patients, including social and environmental inequalities and deprivation, which affect their social cohesion and capacity to respond to situations of social risk6. It is associated with the health/disease process and encompasses various individual dimensions linked to exposure to risk factors and threats ${ }^{6,7}$. It includes consideration of access to food, public health services and the ability to actively respond to risks ${ }^{8}$. Understanding social vulnerability helps to identify and understand which group of people may be more sensitive and susceptible to a disease condition and why ${ }^{9}$. Understanding this will help governments respond appropriately to the needs of vulnerable populations by promoting targeted interventions and strategies, and increase future social capacity and resilience?.

Vulnerability increases risk for diseases and other stressors for individuals who live especially in conditions of poverty. Poverty reduces people's ability to cope 
with, recover from, or adapt to external stresses that affect their livelihood and well-being ${ }^{10}$. Data on social vulnerability assessments are the guide for government and international agencies in efforts to reduce individual and community vulnerability to disease and other stressors, and to strengthen the coping mechanisms ${ }^{10}$.

Methods and indicators for assessing vulnerability vary depending on the research or policy context ${ }^{8}$. Several indices to characterize social vulnerability to various issues at different spatial scales were developed over the past decade ${ }^{11-13}$. Some of the variables in indices used for measuring social vulnerability include residential area ${ }^{14}$ socioeconomic status ${ }^{5}$, educational status $^{15}$ and financial status ${ }^{16}$. These same measures had been used over the years to assess the vulnerability of individuals and communities to diseases, as they reflect how the material reality of life increases the predisposition to poor nutrition ${ }^{17}$ and serves as barrier to access health services, due to the cost of medical care and distance to facilities ${ }^{13,18}$, among other things.

Numerous studies that examined the associations between socio-demographic, economic and individual factors such as race $^{19}$, ethnicity ${ }^{20}$, socioeconomic status ${ }^{21}$, oral health literacy ${ }^{22}$ and compliance ${ }^{23}$, and oral health outcomes. The outcomes of these measurements are complex with many of the studies conducted in developed countries. The studies on vulnerability to health has a relatively brief history in low- and middle-income countries. Publication of the findings of such research just started to appear in the late 20 th century ${ }^{3}$.

Studies on social vulnerability to oral health are less common, especially from developing nations like Nigeria. The few direct studies on social vulnerability to oral diseases explore social vulnerability of adults to oral disease ${ }^{14,24}$ and fewer studies examined social vulnerability of children to oral diseases $^{25-28}$.

No studies were identified measuring the social vulnerability of children from an African country to oral diseases, when a Pubmed and Google scholar search was made for this study. In view of the need to determine the vulnerability of individuals and populations to diseases as an important public health response, this study aimed to develop an index for social vulnerability to caries for children in Ile-Ife, Nigeria; and to determine the association between the social vulnerability to caries and the actual caries status of children in the study location.

\section{Material and methods}

This was an analysis of secondary data generated by a household survey. Part of the study was reported by Kolawole et al. ${ }^{29}$ and Folayan et al. ${ }^{30}$. The study recruited 992 children aged 1-12 years for assessing the association between digit-sucking and caries.

Data were obtained by a questionnaire administered by experienced field workers who had been engaged in past national surveys and trained on the study protocol.

The interviewers collected all information from respondents and submitted to survey supervisors who reviewed the questionnaires. Mothers were requested to respond on behalf of children below eight years, based on evidence that responses of mothers on questionnaires have a higher correlation with children's response ${ }^{31}$. Where the mother was unavailable, fathers completed the questionnaires. The socio-demographic characteristics were obtained for each child. Information from the interview included number of siblings, age at last birthday, gender, socioeconomic status, maternal level of knowledge on caries prevention practices and number of meals eaten per day as proxy measure for wealth status ${ }^{32}$.

Study location: The study was conducted in Ife Central Local Government of Ile-Ife, a sub-urban town in Southwestern Nigeria. According to the 2004 National Population Census, the population of the Local Government Area (LGA) was 138,818, with about $14,000(10 \%)$ children among them. The study site also hosted oral health clinics, thereby making it possible to refer for oral health care pupils screened with lesions.

Sample Size Determination: The sample size was calculated using Leslie Fischer's formula ${ }^{32}$ for study population $>10,000$. Based on a prevalence of $34.1 \%$ of oral habits in children aged four to 15 years old, determined by Quashie-Williams et al. ${ }^{33}$, a sample size of 1,011 children was required to identify 345 children with oral habits, with a non-response rate of about $10 \%$.

Sampling Technique: The sampling procedure was a threelevel multi-stage cluster sampling aimed at selecting eligible persons with known probability. Stage 1 involved the random selection of enumeration areas within the LGA; at the sites, every third household on each street was chosen. Stage 2 involved listing eligible individuals within households. Stage 3 involved selection of actual respondents for interview. Only children present in the house at the time of the study were eligible to participate in the study. In the chosen houses only one child was selected. Details of this sampling technique were reported by Kolawole et al. ${ }^{29}$ and Folayan et al. ${ }^{30}$ in an earlier publication from this same database.

Clinical examination: Oral examination was conducted at the homes of all participants to determine the presence of caries and oral hygiene status. The children were examined seated, under natural light, using sterile dental mirrors and probes by trained dentists; radiographs were not used in the study. The teeth were examined wet and debris removed with gauze where present.

Diagnosis of caries: Caries was diagnosed using the World Health Oral Health Survey recommendations ${ }^{34}$. Each tooth was examined for dental caries using a plane mouth mirror, using natural light while the child was seated on a chair. Caries status was assessed using the Decayed Missing and Filled (dmft/DMFT) index. A decayed (d/D) tooth was defined as any which crown had an unmistakable cavitation on pits or fissures, or on a tooth surface or a filled crown with decay, when it had one or more permanent restorations that were decayed. The $\mathrm{f} / \mathrm{F}$ was defined as a filled crown with no decay, when it had one or more permanent restorations, and there were no caries anywhere on the crown. The $\mathrm{m} / \mathrm{M}$ was defined as a tooth missing due to caries; when a tooth had been extracted due to caries. To arrive at a dmft/DMFT score for an individual patient's mouth, three values had to be determined: the number of teeth with carious lesions, the number of extracted teeth due to caries and the number of teeth with fillings or crowns ${ }^{35}$. The number of teeth was then summed to give the dmft/DMFT score for the permanent dentition. For the purpose of analysis, caries status was further divided into present or absent caries.

Social Vulnerability to Caries Scale: This study adapted the method by Tirapanildos et al. ${ }^{36}$ to develop a scale that assessed 
the social vulnerability of study participants to caries. Social vulnerability to caries was defined according to the results of factor analysis, cluster analysis, and discriminant analysis conducted using individual and social caries-predictive variables for the study participants in the study area from six variables. The six candidate variables for the vulnerability scale were gender of the child, maternal knowledge of caries prevention, socioeconomic category of the child, child's age, number of siblings the child had and the number of meals the child had per day. These variables were the social factors associated with the risk of caries in children in the study by prior studies. They include child's age, sex, socioeconomic status, number of siblings and maternal knowledge of oral health: younger children ${ }^{28,29}$, women ${ }^{28-30}$, those with lower socioeconomic status $^{30}$, children with mothers who had poor knowledge of oral health ${ }^{30}$, and children with more siblings ${ }^{37}$ had higher risk for caries. We also included number of meals per day as a proxy measure for poverty $^{38}$ in view of evidences that showed a strong association between poverty and health outcomes ${ }^{39,40}$.

A score for maternal knowledge of oral health was created by summing up 8 items that assessed maternal knowledge. The questions asked if the respondents agreed or disagreed with the following statements: "Fluoridation of drinking water is an effective, safe and efficient way to prevent holes from forming on the teeth'; 'Use of fluoride-containing toothpaste is an effective, safe and efficient way to prevent holes from forming on the teeth'; 'The number of times you eat sugar containing food has a great role in producing holes in the teeth'; 'Fissure sealant is effective in the prevention of holes developing in newly erupted molars'; 'Rinsing teeth with a lower amount of water after tooth-brushing reduces the risk of caries', 'Using fluoride toothpaste is more important than the brushing per se for preventing holes from forming on the teeth', 'Brushing twice daily with fluoride containing toothpaste is effective for preventing holes from developing in the teeth'; and 'It is important to visit the dental clinic regularly as a measure for preventing holes from forming in the teeth'. The ensuing score was dichotomized into poor and good knowledge using $\mathrm{K}$ means cluster analysis.

A correlation matrix of the six candidate variables for the vulnerability scale showed that the highest correlation coefficient between any pair of variables was 0.317 , between number of siblings and child's age group; this correlation was statistically significant $(p<0.001)$. Therefore, the variable for number of siblings was dropped from the scale because the age of the child was considered a more important variable for assessing social vulnerability to caries. The five remaining items for the social vulnerability to caries scale were subjected to factor analysis. Assessment of suitability of the data for factor analysis showed that the Kaiser-Meyer-Oklin value was 0.51 , exceeding the recommended value of 0.5 and the Barlett's Test of Sphericity41 reached statistical significance, supporting the factorability of the correlation matrix. Factor analysis using principal components showed the five items could be grouped into two factors with Eigen-value exceeding 1 and explaining $23.1 \%$ and $22.1 \%$ of the variance respectively. It was decided to retain both factors (Table 1).

The five items were joined to give the social vulnerability to caries score and cluster analysis. The $\mathrm{K}$ means was used to create a binary variable for caries vulnerability dividing the score into vulnerable and non-vulnerable categories. Discriminant analysis was used to validate the grouping created by $\mathrm{K}$ means cluster analysis. A model that allowed for classification of all patients into vulnerable and non-vulnerable groups was developed and validated using the Wilks' Lambda test. The test indicated that the model was appropriate for the study population: among 992 children, 100\% were classified correctly by the proposed model, indicating that the proposed allocation process would ensure correct classification (Tables 2 and 3).

Table 1 - Results of factor analysis.

\begin{tabular}{|c|c|c|}
\hline Validation of factor analysis & & $\%$ of variability \\
\hline KMO & 0.51 & 23.1 \\
\hline Bartlett test & 28.85 & 22.1 \\
\hline $\mathrm{p}$-value & $<0.001$ & \\
\hline Factor loadings (rotated) ${ }^{*}$ & $\begin{array}{l}\text { Factor } 1 \\
\text { Individual factor }\end{array}$ & $\begin{array}{l}\text { Factor } 2 \\
\text { Household factor }\end{array}$ \\
\hline Socio economic status & 0.61 & \\
\hline Child's age group & 0.61 & \\
\hline Child's gender & -0.59 & \\
\hline Average number of meals per day & & 0.73 \\
\hline Maternal knowledge of caries & & 0.69 \\
\hline
\end{tabular}

${ }^{*}$ Considered values $>+0.40$ or $<-0.40$ for better understanding

Table 2 - Results of cluster analysis using data of 992 study participants in Ile-Ife.

\begin{tabular}{llll}
\hline Group & Number & Percentage & Percentage valid \\
Vulnerable & 684 & $69.0 \%$ & $70.7 \%$ \\
Non-vulnerable & 283 & $28.5 \%$ & $29.3 \%$ \\
Omitted from the study & 25 & $2.5 \%$ & - \\
\hline Total & 992 & 100.0 & 100.0 \\
\hline
\end{tabular}

Table 3 - Results of discriminant analysis using data of 992 study participants in Ile-Ife.

\begin{tabular}{lll}
\hline Group & Number & Percentage \\
Vulnerable & 684 & $70.7 \%$ \\
Non-vulnerable & 283 & $29.3 \%$ \\
\hline Total & 967 & $100.0 \%$ \\
\hline
\end{tabular}

Standardization of clinical examiners: The clinical investigators were qualified dentists undergoing postgraduate residency training as Paedodontists or Orthodontists who were calibrated on the study protocol and the WHO criteria for caries diagnosis, including the dmft/DMFT index and OHI-S. Training was followed by practice on patients; each investigator examined and scored children for oral lesions as prescribed in the study protocol. Results were subjected to a Cohen's weighted Kappa score analysis to determine intra- and inter-examiner variability. The intra-examiner variability ranged between $0.89-0.94$, while inter-examiner variability ranged between $0.82-0.90$ for caries detection.

Data analysis: The profile of study participants was reported by vulnerability classification. Bivariate analysis was conducted to 
test the association between dependent variables (presence of caries and severity of caries measured by the dmft/DMFT score) and the independent variables (socially vulnerable and non-vulnerable groups for caries). Where appropriate, chi square tests were conducted. Multivariate logistic regression was used for inferential analysis. The logistic regression model included only variables whose $\mathrm{p}$ values were $<0.4$ and entered into the subsequent models. The estimated coefficients were expressed as odds ratios (ORs) and their $95 \%$ confidence intervals were also calculated. Statistical analysis was conducted with STATA software (version 11) for the logistic regression. Statistical significance was fixed at $p<0.05$.

Ethical considerations: Ethical approval was obtained from the Ethics and Research Committee of the Obafemi Awolowo University Teaching Hospital Complex Ile-Ife (ERC/2013/07/14). Approval to conduct the study was obtained from the Local Government Authority. The study was conducted in full compliance with the study protocol. Written informed consent was obtained from the parents of study participants after duly explaining study objectives, risks and benefits, voluntary nature of participation and freedom to withdraw at any time. All children aged eight to 12 years also provided written assent. Efforts to minimize risks such as loss of confidentiality and discomfort to participants were made. All data were collected without the identifier (names and addresses) of participants. Participants experienced no direct benefit and no compensation was paid, however they were given token gifts of stationery or a small tube of toothpaste. None of the gifts exceeded $\$ 0.50$.

\section{Results}

Table 4 shows the outcome of the association between social vulnerability, the dmft/DMFT and presence of caries. There was no significant association found between the social vulnerability for caries and the $\operatorname{dmft}(p=0.64)$, the DMFT $(p=0.78)$, a combination of dmft and DMFT $(p=0.28)$ and the dental caries status $(p=0.53)$.

Table 4 - Social Vulnerability, dmft, DMFT and presence of caries.

\begin{tabular}{|c|c|c|c|c|c|}
\hline \multirow{3}{*}{ Variables } & \multicolumn{4}{|c|}{ Social vulnerability } & \multirow[t]{3}{*}{$\begin{array}{l}\text { Chi square test } \\
\text { Fisher's exact }\end{array}$} \\
\hline & \multicolumn{2}{|c|}{ Non-vulnerable $(\mathrm{n}=684)$} & \multicolumn{2}{|c|}{ Vulnerable $(n=283)$} & \\
\hline & Freq & $\%$ & Freq & $\%$ & \\
\hline \multicolumn{6}{|l|}{$\mathrm{dmft}$} \\
\hline 0 & 611 & 89.3 & 258 & 91.2 & \multirow{9}{*}{$p=0.64$} \\
\hline 1 & 31 & 4.5 & 8 & 2.8 & \\
\hline 2 & 27 & 3.9 & 8 & 2.8 & \\
\hline 3 & 6 & 0.9 & 4 & 1.4 & \\
\hline 4 & 3 & 0.4 & 2 & 0.7 & \\
\hline 5 & 2 & 0.3 & 2 & 0.7 & \\
\hline 6 & 1 & 0.1 & 1 & 0.4 & \\
\hline 8 & 2 & 0.3 & 0 & 0.0 & \\
\hline 9 & 1 & 0.1 & 0 & 0.0 & \\
\hline \multicolumn{6}{|l|}{ DMFT } \\
\hline 0 & 666 & 97.4 & 276 & 97.5 & \multirow{6}{*}{$p=0.78$} \\
\hline 1 & 11 & 1.6 & 4 & 1.4 & \\
\hline 2 & 4 & 0.6 & 1 & 0.4 & \\
\hline 3 & 0 & 0.0 & 1 & 0.4 & \\
\hline 4 & 2 & 0.3 & 1 & 0.4 & \\
\hline 9 & 1 & 0.1 & 0 & 0.0 & \\
\hline \multicolumn{6}{|l|}{ Dmft + DMFT } \\
\hline 0 & 602 & 88.0 & 253 & 89.4 & \multirow{10}{*}{$p=0.28$} \\
\hline 1 & 33 & 4.8 & 11 & 3.9 & \\
\hline 2 & 30 & 4.4 & 7 & 2.5 & \\
\hline 3 & 8 & 1.2 & 4 & 1.4 & \\
\hline 4 & 4 & 0.6 & 5 & 1.8 & \\
\hline 5 & 2 & 0.3 & 2 & 0.7 & \\
\hline 6 & 0 & 0.0 & 1 & 0.4 & \\
\hline 7 & 1 & 0.1 & 0 & 0.0 & \\
\hline 8 & 3 & 0.4 & 0 & 0.0 & \\
\hline 18 & 1 & 0.1 & 0 & 0.0 & \\
\hline \multicolumn{6}{|l|}{ Dental caries } \\
\hline No caries & 602 & 88.0 & 253 & 89.4 & \multirow{4}{*}{$p=0.53$} \\
\hline In primary dentition & 64 & 9.4 & 23 & 8.1 & \\
\hline In permanent dentition & 10 & 1.5 & 6 & 2.1 & \\
\hline In primary and permanent dentition & 8 & 1.2 & 1 & 0.4 & \\
\hline
\end{tabular}


Table 5 - Frequency distribution and results of logistic regression analysis for predictors of caries status in a sample of 992 children.

\begin{tabular}{|c|c|c|c|c|c|c|}
\hline \multirow{2}{*}{ Variables } & Caries absent & Caries present & \multirow{2}{*}{ OR } & \multirow{2}{*}{ p-value } & \multirow{2}{*}{ AOR } & \multirow{2}{*}{$p$-value } \\
\hline & Frequency (\%) & Frequency (\%) & & & & \\
\hline \multicolumn{7}{|l|}{ Gender } \\
\hline Male & $462(52.7)$ & $46(39.7)$ & 1 & - & 1 & \\
\hline Female & $414(47.3)$ & $70(60.3)$ & $1.70(1.14-2.52)$ & 0.009 & $1.63(1.08-2.46)$ & 0.02 \\
\hline \multicolumn{7}{|c|}{$\begin{array}{l}\text { Maternal knowledge of } \\
\text { caries prevention }\end{array}$} \\
\hline Good & $506(57.8)$ & $68(58.6)$ & 1 & - & & \\
\hline Poor & $370(42.2)$ & $48(41.4)$ & $0.96(0.65-1.43)$ & 0.86 & - & - \\
\hline \multicolumn{7}{|c|}{ Socioeconomic Status } \\
\hline High & $281(32.1)$ & $41(35.7)$ & 1 & - & & \\
\hline Low/moderate & $595(67.9)$ & $74(64.3)$ & $0.85(0,57-1.28)$ & 0.44 & - & - \\
\hline \multicolumn{7}{|l|}{ Age } \\
\hline$\geq 5$ years & $512(58.4)$ & $89(76.7)$ & 1 & - & 1 & \\
\hline Under 5 years & $364(41.6)$ & $27(23.3)$ & $0.43(0.27-0.67)$ & $<0.001$ & $0.62(0.39-1.00)$ & 0.05 \\
\hline \multicolumn{7}{|c|}{ Number of Siblings } \\
\hline 2 or less & $414(47.5)$ & $26(22.8)$ & 1 & - & 1 & \\
\hline More than 2 & $458(52.5)$ & $88(77.2)$ & $3.05(1.93-4.83)$ & $<0.001$ & $2.61(1.61-4.24)$ & $<0.001$ \\
\hline \multicolumn{7}{|c|}{ Number of Meals Per Day } \\
\hline 2 or less & $844(98.7)$ & $110(97.3)$ & 1 & - & 1 & \\
\hline More than 2 & $11(1.3)$ & $3(2.7)$ & $2.09(0.57-7.62)$ & 0.26 & $2.49(0.66-9.53)$ & 0.18 \\
\hline \multicolumn{7}{|c|}{ Social vulnerability to caries } \\
\hline Non vulnerable & $602(70.4)$ & $82(73.2)$ & 1 & - & & \\
\hline Vulnerable & $253(29.6)$ & $30(26.8)$ & $0.87(0.55-1.36)$ & 0.54 & - & $=$ \\
\hline
\end{tabular}

Table 5 shows the predictors of caries status. With simple logistic regression analysis, the social vulnerability to caries status of the child was not a significant predictor of caries status. Rather, children classified as socially vulnerable to caries had insignificantly lower odds of having caries than children classified as socially vulnerable to caries. (OR: 0.87; 95\% CI: $0.55-1.36 ; \mathrm{p}=0.54)$. The significant predictors of caries status were sex, number of siblings and age: women had significantly higher odds of having caries than men (OR: 1.70; $95 \%$ CI: $1.14-2.52 ; p=0.009)$; children with more than two siblings had higher odds of having caries than children with 2 or less siblings (OR: 3.05; 95\% CI: $1.93-4.83$; $<<0.001$ ); and children under 5 years of age had significantly higher odds of having caries than children 5 years and older (OR: $0.43 ; 95 \%$ CI: $0.27-0.67 ; \mathrm{p}<0.001)$.

Following adjustment for confounders, the three significant predictors of presence of caries were sex, age and number of siblings. Women had significantly higher odds of having caries than men (AOR: 1.63; 95\% CI: $1.08-2.46$; $p=0.02$ ). Children under the age of 5 were less vulnerable to caries than children five years and above (AOR: 0.62 ; 95\% CI: $0.39-1.00$; $\mathrm{p}=0.05$ ); and children with more than two sibling children had higher odds of having caries than children with two or less siblings (AOR: 2.61; 95\% CI: $1.61-4.24$; $\mathrm{p}<0.001$ ).

\section{Discussion}

The study showed that the developed social vulnerability index for caries was not a sensitive determinant of caries status for this study population. Rather, the study found that gender, age of the child and the number of siblings were the three social variables predictive of caries status of children in the study population.

These findings have a few implications. First, our findings may imply that the social vulnerability of each child is not a determinant of its caries status in the study population. Rufai et al. ${ }^{42}$ also noted that exclusion of social vulnerability dimensions pertinent to specific hazards or the overrepresentation of weakly influential dimensions may lead to misleading conclusions about social vulnerability. Conscientious effort was made to develop a social vulnerability index for caries that included social vulnerability dimensions identified earlier by multiple studies as social risk factors for caries for individuals in the study population. The use of location-specific variables to construct a contextually specific social vulnerability index for caries in this study was based on the understanding that geographical and time-varying characteristics are important and essential for deconstructing vulnerability ${ }^{42-44}$. The developed index was found appropriate for the population, and the Wilks' Lambda test indicated that the proposed allocation process would ensure correct classification.

The development of a quantitative indicator to measure caries risk for this study population with low caries prevalence ${ }^{45}$ was important because a sensitive and specific index can facilitate the identification of populations most vulnerable to caries. This in-turn, can enhance political decision making processes about resource allocation and project prioritization especially in a limited resource setting like Nigeria. This study found that the developed social vulnerability for caries index developed was not a sensitive and specific tool for determining caries status in the study population. 
The tool development process had a limitation: the variables in the index were allotted equal weights in the model. Weights usually have an important impact on the composite indicator value and are based on statistical adequacy, social and economic significance among others 46 . However, weights are based on value judgment increasing the propensity to introduce bias and possibly affecting the comparison of data across countries ${ }^{46}$. Unfortunately, while we had evidence to justify the variables derived for the construction of the composite index, we did not have the evidence required to make the needed value judgement to place weights on any of the components of the composite index. We intend to conduct further studies to identify how weights can be allotted to the composite variables in the developed index and use this information to refine the current index. We will then evaluate if the refined index for social vulnerability to caries can be more sensitive for assessing caries status in the study population.

Divaris $^{47}$ also highlighted the limitations of attempting to transfer and apply population-derived risk estimates to individual risk assessment. He called this the privatization of risk and it can be misleading, as the risk factors may be insufficient to cause diseases at the individual level. Rather, individual level caries risk assessment should be made at the tooth level. The findings of this study may be a validation of this postulation.

The study outcomes may also be an indication that social conditions may be reflective of vulnerability in populations with high risk for caries or in highly heterogenic societies where race and ethnicity are factors for social inequity and vulnerability for diseases and health outcomes. The social environment in Ile-Ife is highly homogenous, with little disparity in race and ethnicity. This made it difficult to include ethnicity as a variable in the composite index developed to measure social vulnerability to caries.

The study outcome may also reflect the limitations of using social vulnerability for assessing individual caries status in the study population. There are multiple efforts made to help increase the precision of dentists in taking decisions about the caries risk of individuals at their care. However, the use of a social vulnerability to caries index goes beyond being clinically applicable; the focus is to develop a quantitative assessment tool that can enhance the translation of oral health care research into policies and programs that benefit the general population. Vulnerability assessment may help governments develop effective responses to the needs of vulnerable populations. The development of a social vulnerability to caries index can serve this purpose though we do acknowledge that translating social vulnerability processes into composite indicators can indeed be a complex endeavor. Further research efforts are therefore required to help develop a social vulnerability index for children that can help facilitate government's effort to prioritize its limited resources to respond to the children most vulnerable to caries.

The three significant risk factors identified as independent predictors of caries status in this study were female children, children older than 5 years and children with more than two siblings. Although these variables were included in the developed social vulnerability for caries index, the index was still not predictive of caries status although these factors were. Further qualitative and quantitative studies are required to understand the role these three variables play in increasing the risk of children to caries in the study environment.

\section{References}

1. Wolf S, Hinkel J, Hallier M, Bisaro A, Lincke D, lonescu C, et al. Clarifying vulnerability definitions and assessments using formalisation. Int J Climate Change Strateg Manage. 2013;5(1):54-70. doi: 10.1108/17568691311299363.

2. Blaikie P, Cannon T, Davis I, Wisner B. At risk: Natural hazards, people's vulnerability, and disasters. Routledge: London; 1994.

3. Singh SP, Eghdami MR, Singh S. The Concept of Social Vulnerability: A Review from Disasters Perspectives. Int J Interdiscip Multidiscip Stud. 2014;1(6):71-82.

4. Lee YJ. Social vulnerability indicators as a sustainable planning tool. Environ Impact Assess Rev. 2013;44:31-42. doi: 10.1016/j. eiar.2013.08.002.

5. Sajjad H, Jain P. Assessment of socio-economic vulnerabilities among urban migrants in south-east Delhi, India. J Stud Social Sci. 2014;7(1):65-81.

6. Andrew MK, Mitnitski AB, Rockwood K. Social vulnerability, frailty and mortality in elderly people. PLoS One. 2008 May 21;3(5):e2232. doi: 10.1371/journal.pone.0002232.

7. Howe LD, Galobardes B, Matijasevich A, Gordon D, Johnston $D$, Onwujekwe $\mathrm{O}$, et al. Measuring socio-economic position for epidemiological studies in low- and middle-income countries: a methods of measurement in epidemiology paper. Int J Epidemiol 2012 Jun;41(3):871-86. doi: 10.1093/ije/dys037.

8. Hinkel J. Indicators of vulnerability and adaptive capacity: Towards a clarification of the science-policy interface. Glob Environ Change. 2011;21(1):198-208. doi: 10.1016/j.gloenvcha.2010.08.002.

9. Tapsell S, McCarthy S, Faulkner H, Alexander M. Social vulnerability and natural hazards. CapHaz-Net WP4 Report, Flood Hazard Research Centre - FHRC. London: Middlesex University; 2010

10. Stanturf JA, Goodrick SL, Warren ML Jr, Charnley S, Stegall CM. Social vulnerability and Ebola virus disease in rural Liberia. PLoS One. 2015 Sep 1;10(9):e0137208. doi: 10.1371/journal.pone.0137208.

11. Cutter SL, Finch C. Temporal and spatial changes in social vulnerability to natural hazards. Proc Natl Acad Sci U S A. 2008 Feb 19;105(7):2301. 6. doi: 10.1073/pnas. 0710375105 .

12. Abson DJ, Dougill AJ, Stringer LC. Using principal component analysis for information-rich socio-ecological vulnerability mapping in Southern Africa. Appl Geog. 2012 Nov;35(1):515-24. doi: 10.1016/j. apgeog.2012.08.004

13. Barata RB, Ribeiro MC, Cassanti AC, Grupo do Projeto Vulnerabilidade Social no Centro de São Paulo. Social vulnerability and health status: a household survey in the central area of a Brazilian metropolis. Cad Saude Publica. 2011;27(suppl 2):S164-75. doi: 10.1590/S0102311X2011001400005.

14. Bendo CB, Vale MP, Figueiredo LD, Pordeus IA, Paiva SM. Social vulnerability and traumatic dental injury among Brazilian schoolchildren: a population-based study. Int J Environ Res Public Health. 2012; 9(12):4278-91.

15. Muttarak R, Lutz W. Is education a key to reducing vulnerability to natural disasters and hence unavoidable climate change? Ecol Soc. 
2014;19(1):42. doi: 10.5751/ES-06476-190142.

16. Zaman G, Vasile V. Economic-financial and social vulnerabilities of Romania in the period 2013-2020. Procedia Econ Financ. 2014;15:4-18. doi: 10.1016/S2212-5671(14)00439-0.

17. Frozi DS, Sichieri R, dos Santos SMC, Pereira RA. Characteristics of Social Vulnerability and Food Insecurity among Urban Families in Extreme Poverty in Brazil. J Food Secur. 2015;3(2):62-8. doi: 10.12691/ jfs-3-2-4.

18. Grabovschi C, Loignon C, Fortin M. Mapping the concept of vulnerability related to health disparities: a scoping review. BMC Health Serv Res. 2013 Mar 12;13:94. doi: 10.1186/1472-6963-13-94.

19. Butani $Y$, Weintraub JA, Barker JC. Oral health-related cultural beliefs for four racial/ethnic groups: Assessment of the literature. BMC Oral Health. 2008 Sep 15;8:26. doi: 10.1186/1472-6831-8-26.

20. Cruz GD, Chen Y, Salazar CR, Le Geros RZ. The association of immigration and acculturation attributes with oral health among immigrants in New York City. Am J Public Health. 2009 Oct;99 Suppl 2:S474-80. doi: 10.2105/AJPH.2008.149799.

21. Teodora T, Dănilă I. Socioeconomic status and oral health. J Prevent Med. 2005;13(1-2):116-21.

22. Ueno M, Takeuchi S, Oshiro A, Kawaguchi Y. Relationship between oral health literacy and oral health behaviors and clinical status in Japanese adults. J Dent Sci. 2013 Jun;8(2):170-6. doi: 10.1016/j.jds.2012.09.012.

23. Ramsay DS. Patient compliance with oral hygiene regimens: a behavioural self-regulation analysis with implications for technology. Int Dent J. 2000;Suppl Creating A Successful:304-11.

24. Fadel CB, Langoski JÉ, Machado MI, Stremel JM, Bordin D, Madalozo JA. Understanding of socially vulnerable individuals on oral health and access to dentist: A Brazilian study. Open J Prev Med. 2014 Nov;4(11):868-75. doi: 10.4236/ojpm.2014.411098.

25. Martins MT, Sardenberg F, Vale MP, Paiva SM, Pordeus IA. Dental caries and social factors: impact on quality of life in Brazilian children. Braz Oral Res. 2015;29(1):S1806-83242015000100310. doi: 10.1590/18073107BOR-2015.vol29.0133.

26. Bendo CB, Paiva SM, Torres CS, Oliveira AC, Gours D, Pordeus IA, Vale MP. Association between treated/untreated traumatic dental injuries and impact on quality of life of Brazilian schoolchildren. Health Qual Life Outcomes. 2010 Oct 4;8:114. doi: 10.1186/1477-7525-8-114.

27. Carvalho ML, Moysés SJ, Bueno RE, Shimakura S, Moysés ST. A geographical population analysis of dental trauma in school-children aged 12 and 15 in the city of Curitiba, Brazil. BMC Health Serv Res. 2010 Jul 13;10:203. doi: 10.1186/1472-6963-10-203.

28. Folayan MO, Owotade FJ, Ozeigbe E, Fadeyibi R. Effect of birth rank on the caries experience of children from a Suburban population in Nigeria. J Dent Oral Hyg. 2010 Sep;2(3):27-30.

29. Kolawole KA, Folayan MO, Agbaje HO, Oyedele TA, Oziegbe EO, Onyejaka NK, et al. Digit sucking habit and association with dental caries and oral hygiene status of children aged 6 months to 12 years in semi-urban Nigeria. PLoS One. 2016 Feb 18;11(2):e0148322. doi: 10.1371/journal.pone.0148322.

30. Folayan MO, Kolawole KA, Oziegbe EO, Oyedele T, Oshomoji OV, Chukwumah NM, et al. Prevalence, risk factors and predictors of early childhood caries in children resident in sub-urban Nigeria . BMC Oral Health. 2015 Jun;15:72. doi: 10.1186/s12903-015-0058-y.

31. Folayan $\mathrm{MO}$, Idehen $\mathrm{EE}, \mathrm{Ojo} \mathrm{OO}$. Dental anxiety in a subpopulation of African children: parents' ability to predict and its relation to general anxiety and behaviour in the dental chair. Eur J Paediatr Dent. 2004 Mar;5(1):19-23.

32. Araoye MO. Sample size determination: In research methodology with statistics for health and social sciences. Ilorin: Nathadex Publishers; 2003.

33. Quashie-Williams R, daCosta 00 , Isiekwe MC. Oral habits, prevalence and effects on occlusion of 4-15 year old school children in Lagos, Nigeria. Niger Postgrad Med J. 2010 Jun;17(2):113-7.

34. WHO. World Health Organization. Oral Health Surveys: Basic Methods. Geneva: WHO; 1997.

35. Krapp K. Dental indices. Encyclopedia of Nursing \& Allied Health: Gale Cengage. Michigan: Farmington Hills; 2012.

36. Tirapanildos S, Pinheiro HS, Mansur HN, Oliveira DD, Huaira RM, Huaira $\mathrm{CC}$, et al. Impact of social vulnerability on the outcomes of predialysis chronic kidney disease patients in an interdisciplinary center. J Bras Nefrol. 2015 Jan-Mar;37(1):19-26. doi: 10.5935/0101-2800.20150004.

37. Onyejaka N. Factors affecting utilization of oral health care services among primary school pupils aged 8-11 years in Enugu State, Nigeria [dissertation unpublished]. Faculty of Surgery of the National Postgraduate Medical College of Nigeria in partial fulfilment of the award of the Fellowship of the College; 2014.

38. Folayan MO, Odetoyinbo M, Harrison A. Differences in use of contraception by age, sex and HIV status of 10-19-year-old adolescents in Nigeria. Int J Adolesc Med Health. 2015 Nov 10. pii: /jlijamh. ahead-of-print/ijamh-2015-0059/ijamh-2015-0059.xml. doi: 10.1515/ ijamh-2015-0059.

39. Raphael D. Poverty in childhood and adverse health outcomes in adulthood. Maturitas. 2011 May;69(1):22-6. doi: 10.1016/j. maturitas.2011.02.011.

40. Wagstaff A. Poverty and health sector inequalities. Bull World Health Organ. 2002;80(2):97-105.

41. Bartlett MS. A note on the multiplying factors for various chi square approximations. J R Stat Soc Series B Stat Methodol. 1954;16:296-8.

42. Rufai $S$, Tate $E$, Burton CG, Maroof AS. Social vulnerability to floods: Review of case studies and implications for measurement. Int $\mathrm{J}$ Disaster Risk Reduct. 2015;14(4):470-86. doi: 10.1016/j.ijdrr.2015.09.013.

43. Kasperson RE, Dow K, Golding D, Kasperson JX, editors. Understanding global environmental change: the contributions of risk analysis and management. Worcester, MA: Clark University; 1990. p.27-44.

44. Mitchell JK, Devine N, Jagger K. A contextual model of natural hazard. Am Geogr Soc. 1989 Oct;79(4):391-409.

45. Petersen P. Sociobehavioural risk factors in dental caries - international perspectives. Community Dent Oral Epidemiol. 2005 Aug;33(4):274-9.

46. Composite Indicators Research Group. Weighting. 2016 [cited 2016 May 15]. Available from: https://composite-indicators.jrc.ec.europa. eu/?q=content/step-6-weighting.

47. Divaris K. Predicting dental caries outcomes in children: a 'risky' concept. J Dent Res. 2016 Mar;95(3):248-54. doi: 10.1177/0022034515620779. 